\title{
Misalignment fading effects on the ACC performance of relay- assisted MIMO/FSO systems over atmospheric turbulence channels
}

\author{
Huu Ai Duong ${ }^{1}$, Van Loi Nguyen ${ }^{2}$, Khanh Ty Luong ${ }^{2}$ \\ ${ }^{1}$ Faculty of Computer Engineering and Electronics, The University of Danang, Vietnam-Korea University of Information and \\ Communication Technology, Danang, Vietnam \\ ${ }^{2}$ Faculty of Computer Science, The University of Danang, Vietnam-Korea University of Information and Communication Technology, \\ Danang, Vietnam
}

\begin{tabular}{l}
\hline \hline Article Info \\
\hline Article history: \\
Received Jan 15, 2021 \\
Revised Aug 11, 2021 \\
Accepted Sep 2, 2021
\end{tabular}

Keywords:

AF relay

Atmospheric turbulence

Average channel capacity

FSO communication

Misalignment fading

\begin{abstract}
The continuous development of internet of things (IoT) technology enables many devices to be interconnected through the external environment. Meanwhile, 5G technology provides an enhanced quality of services with high data transmission rates, requiring IoT implementation in the $5 \mathrm{G}$ architecture. Free-space optical communication (FSO) is considered a promising technique that can provide high-speed communication links, so FSO is an optimal choice for wireless networks to fulfill the full potential of $5 \mathrm{G}$ technology, providing speeds of $100 \mathrm{~Gb} / \mathrm{s}$ or more. By implementing 5G features in IoT, IoT coverage and performance will be enhanced by using FSO models. Therefore, the paper proposed and investigated the multipleinput and multiple-output/free-space optical communication (MIMO/FSO) model using subcarrier quadrature amplitude modulation (SC-QAM) and relay stations over atmospheric turbulence channels by log-normal and gamma-gamma distribution under different turbulence conditions. The performance is examined based on the average channel capacity (ACC), which is expressed in terms of average spectral efficiency (ASE) parameters while changing the different parameters of the model. The mathematical formulas of ACC for atmospheric turbulence cases are calculated and discussed the influence of turbulence strength, the different number of relay stations, misalignment effects, and different MIMO configurations.
\end{abstract}

This is an open access article under the CC BY-SA license.

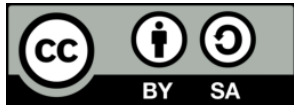

\section{Corresponding Author:}

Huu Ai Duong

Faculty of Computer Engineering and Electronics, The University of Danang, Vietnam-Korea University of Information and Communication Technology

Danang, Vietnam

Email: dhai@vku.udn.vn

\section{INTRODUCTION}

Free space optical communication is considered a promising technique that can provide high-speed communication links. Free-space optical communication (FSO) systems have always been proved necessary because of a license-free, cost-effective, high-bandwidth and high-security access technique [1]-[3]. There is a significant degradation in the performance of FSO communications caused by atmospheric turbulence along the laser beams propagation path [4]. Safari and Uysal [5] have derived the relay-assisted free-space optical communication. Kamiri and Kerari [6] has formulated and analyzed the bit error rate (BER) analysis of cooperative systems in free-space optical networks, with some recent studies on the channel model for amplify-and-forward (AF) systems [7]-[14]. 
Further, the error performance of FSO systems using sub-carrier modulation schemes has been extensively investigated in [15]-[27]. On the subject of subcarrier quadrature amplitude modulation (SC-QAM) systems, the average symbol error probability of the single-input and single-output (SISO) FSO systems over atmospheric turbulence channels is presented in [17]. Recently, Hassan et al. [20] evaluated the sub-carrier intensity modulation in wireless optical communications. Bayaki et al. [21] investigated the performance of multiple-output (MIMO) FSO system under the gamma-gamma fading model using the modified Bessel function. Gripeos et al. [22] presented the average channel capacity (ACC) of MIMO FSO systems with different atmospheric turbulence conditions. However, an analyst is of the performance of an AF FSO system over atmospheric turbulence and misalignment fading is not yet available.

This paper presents a theoretical analysis of the misalignment fading effects on the ACC performance of AF relay-assisted MIMO/FSO systems over atmospheric turbulence channels in section 1 . Section 2 described the system model in detail. Next, the average channel capacity is presented in section 3. Section 4 discusses the results and concludes at the end.

\section{SYSTEM MODEL}

\subsection{AF relay-assisted MIMO/FSO systems}

A typical serial multi-hop MIMO FSO system using SC-QAM signals with $M$ transmitting lasers are pointing toward an $N$ aperture receiver as depicted in Figure 1. The system comprises of source node, relaying node, and destination node.
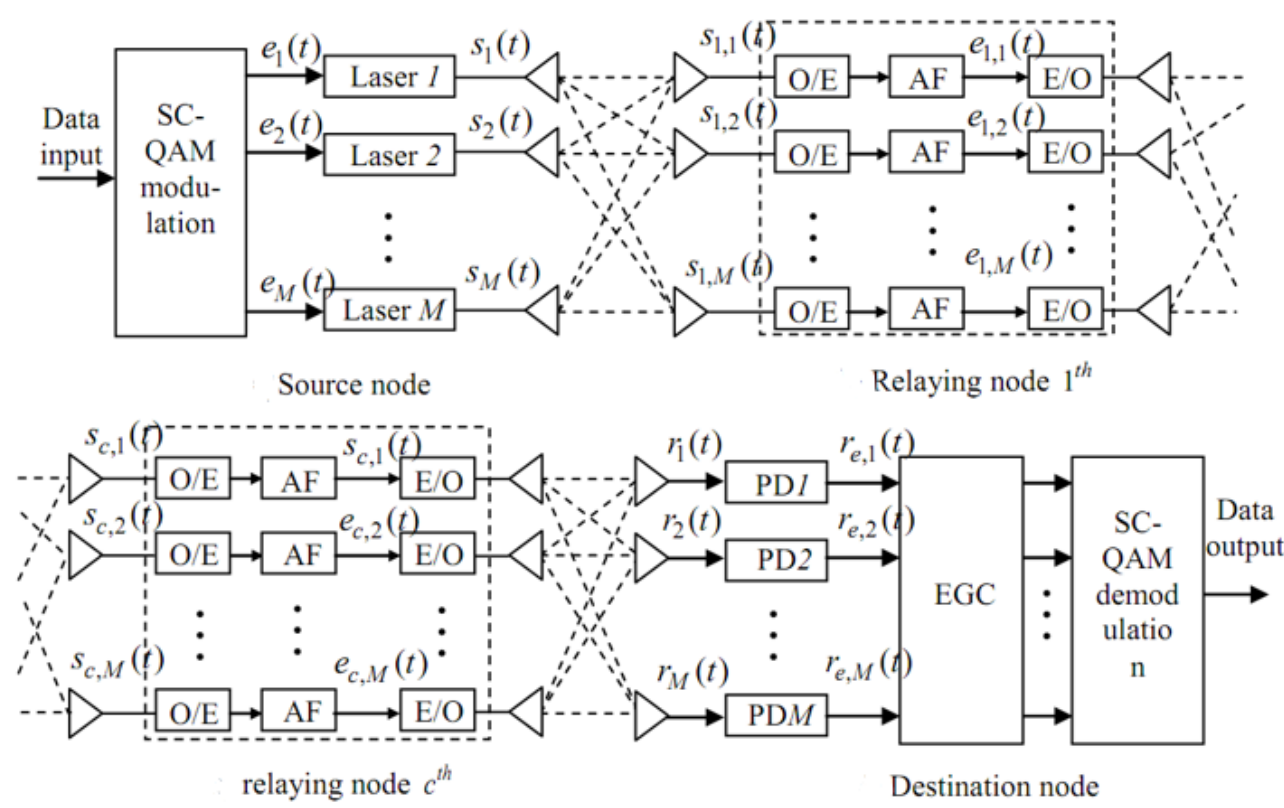

Figure 1. The source node, relaying node and destination node of AF-MIMO/FSO systems

All relay nodes are assumedly to receive and transmit signals concurrently in the same frequency band. The channel model of MIMO/FSO systems can be expressed by the $M \times N$ matrix, which is denoted by $X=\left[X_{m n}\right]_{m, n=1}^{M, N}$. The electrical signal at the input of the QAM demodulator of the destination node can be described as (1) [21],

$$
r_{e}(t)=P_{s} e(t) \kappa\left[\sum_{m=1}^{M} \sum_{n=1}^{N} \prod_{i=0}^{c+1}\left(X_{i}\right)_{m n} \Re_{i} P_{i}\right]+v_{n \Sigma}
$$

where $\left(X_{i}\right)_{m n}$ denotes the stationary random process of the turbulence channel from the $m^{\text {th }}$ laser to the $n^{\text {th }}$ $\mathrm{PD}, v_{n \Sigma}=\sum_{i=1}^{c+1} v_{n_{i}}$ is the total accumulation noise. In this system model, we use an equal gain combining (EGC) scheme at the destination node to estimate the received signal from sub-channels, the instantaneous electrical SNR will be (2), 


$$
\gamma=\left(\sum_{m=1}^{M} \sum_{n=1}^{N} \prod_{i=0}^{c+1}\left(\sqrt{\gamma_{i_{m n}}}\right)\right)^{2}
$$

where $\mathrm{c}$ is the number of the relay station, $\gamma_{i_{m n}}$ is the random variable (RV) defined as the instantaneous electrical SNR component of the sub-channel from the $m^{\text {th }}$ laser to the $n^{\text {th }} \mathrm{PD}$, it can be described by (3),

$$
\gamma=\frac{\left(\frac{1}{M N} \kappa \Re^{c+1} P_{s} \sum_{m=1}^{M} \sum_{n=1}^{N} \prod_{i=1}^{c+1} X_{i} P_{i}\right)^{2}}{N_{0_{\Sigma}}}=\bar{\gamma}\left(\sum_{m=1}^{M} \sum_{n=1}^{N} \prod_{i=1}^{c+1} X_{i} P_{i}\right)^{2}
$$

where $X_{i}$ denotes the stationary random process pdf the turbulence channel from the $i^{\text {th }} \mathrm{AF}$ to the $(i+1)^{\text {th }} \mathrm{AFR}$ is the photodiode responsivity $P_{S}$ denotes the average transmitted optical power per symbol at each hop, $\kappa(0<\kappa<1)$ is the modulation index, $P_{i}$ is the amplification power of the $i^{\text {th }}$ AF module, $N_{0_{\Sigma}}$ is the total noise variance at a destination node.

\subsection{Atmospheric turbulence channels and misalignment fading models}

In (2) and (3), $X$ represents the channel state, which models the optical intensity fluctuations caused by atmospheric loss, atmospheric turbulence, and misalignment fading channel. With weak atmospheric turbulence, the probability density function (pdf) is described as (4) [23],

$$
f x_{m n}=\frac{\xi^{2} \times X^{\xi^{2}-1}}{(c+1)\left(A_{0} X_{1}\right) \xi^{2}} \frac{1}{2} e^{b} \times \operatorname{erfc}\left(\frac{\operatorname{In}\left(X / X_{l} A_{0}\right)+a}{\sqrt{2 \sigma_{l}}}\right)
$$

where $\alpha=0.5 \sigma_{1}^{2}+\sigma_{1}^{2}\left(\xi^{2}+c\right)$ and $b=\sigma_{1}^{2}\left(\xi^{2}+c\right)\left\{\left(\xi^{2}+c\right)\right\} / 2$.

With moderate to strong atmospheric turbulence conditions, the pdf of is described as (5) [27],

$$
f_{X_{m n}}(X)=\frac{\xi^{2}(\alpha \beta)^{c+1}}{(c+1)\left(A_{0} X_{l}\right) \Gamma(\alpha) \Gamma(\beta)} \times G_{1,3}^{3,0}\left[\alpha \beta \frac{X}{A_{0} X_{l}} \mid \begin{array}{l}
\xi^{2} \\
\left.\xi^{2}-1, \alpha-1-c, \beta-1-c\right]
\end{array}\right]
$$

where $A_{0}=[\operatorname{erf}(v)]^{2}$ is the fraction of the collected power at radial distance $0, v$ is given by $v=$ $\sqrt{\pi r /\left(\sqrt{2 \omega_{z}}\right)}$ with $r$ and $w_{z}$ respectively denote the aperture radius and the beam waist at a distance $z$ and $\xi=\frac{\omega_{z e q}}{2 \sigma s}$, where the equivalent beam radius can be calculated by (6),

$$
\omega_{z e q}=\omega_{z}\left(\sqrt{\pi} \operatorname{erf}(v) / 2 v \times \exp \left(-v^{2}\right)\right)^{2}
$$

where $\omega_{z}=\omega_{0}\left[1+\varepsilon\left(\lambda L / \pi \omega_{0}^{2}\right)^{2}\right]^{1 / 2}$ with $\omega_{0}$ is the transmitter beam waist radius at $z=0, \varepsilon=(1+$ $\left.2 \omega_{0}^{2}\right) / \rho_{0}^{2}$ and $\rho_{0}=\left(0.55 C_{n}^{2} k^{2} L\right)^{-3 / 5}$ is the coherence length, $C_{n}^{2}$ stands for the strength of the atmospheric turbulence, which is the altitude dependent and it is given by (7) [3],

$$
\begin{aligned}
C_{n}^{2}(h)=0.00594 & \left(\frac{v}{27}\right)^{2}\left(10^{-5}\right)^{10} \exp \left(\frac{h}{1000}\right)+C_{n}^{2}(0) \exp \left(-\frac{h}{1000}\right) \\
& +2.7 \times 10^{-6} \exp \left(-\frac{h}{1500}\right)
\end{aligned}
$$

where $h$ is the altitude in meters. $v$ is the wind speed in meters per second, and $C_{n}^{2}(0)$ is the value of $C_{n}^{2}$ at the ground in $\mathrm{m}^{-3 / 2} . C_{n}^{2}$ varies from $10^{-17} \mathrm{~m}^{-3 / 2}$ to $10^{-13} \mathrm{~m}^{-2 / 3}$ for weak up to strong turbulence cases, respectively.

\section{AVERAGE CHANNEL CAPACITY WITH MISALIGNMENT FADING EFFECTS}

Free space optical communication is wireless channel. It is a time variant and random channel. Therefore, to evaluate the channel capacity, we determine the average value, and is denoted $\langle\bar{C}\rangle$. If the 
channel's frequency response is known, the average channel capacity can also be expressed in terms of average spectral efficiency in bits/s/Hz, given by (8) [22].

$$
\langle\bar{C}\rangle=\int_{r} B \log _{2}(1+\gamma \rho) \times f_{r}(\Gamma) d \Gamma,(\mathrm{bit} / \mathrm{s} / \mathrm{Hz})
$$

where $\Gamma=\left\{\gamma_{n m}, n=1, \ldots, N, m=1, \ldots, M\right\}$ is the matrix of the channels, $B$ is the channel's bandwidth and $f_{\Gamma}(\Gamma)$ determined from the components $\gamma_{n m}$.

We obtain the pdfs of AF relay-assisted MIMO/FSO systems over atmospheric turbulence channels. In weak atmospheric turbulence [23] and moderate to strong atmospheric turbulence [27] as (9), (10),

$$
\begin{gathered}
f\left(\gamma_{m n}\right)=\frac{\xi^{2}}{2(c+1)\left(A_{0} X_{l}\right)^{\xi^{2}}} \frac{\gamma_{m n}^{0.5 \xi^{2}-1}}{\gamma_{m n}^{0.5 \xi^{2}}} \frac{1}{\sqrt{\pi}} e^{b} \times \operatorname{erfc}\left(\frac{0.5 \ln \left(\gamma_{m n} / \mathrm{X}_{l}^{2} A_{0}^{2} \bar{\gamma}_{m n}\right)+a}{\sqrt{2} \sigma_{I}}\right) \\
f\left\{\gamma_{m n}\right)=\frac{\xi^{2}(\alpha \beta)^{C+1}}{(c+1)\left(A_{0} X_{1}\right) \Gamma(\alpha) \Gamma(\beta)} \frac{1}{2 \bar{\gamma}_{m n}} \\
\quad \times G_{1,3}^{3,0} \alpha \beta \frac{\left(\gamma_{m n} / \bar{\gamma}_{m n}\right)^{\frac{1}{2}}}{A_{0} X_{1}} \xi^{2}-1, \alpha-1-c, \beta-1-c
\end{gathered}
$$

Substituting (9) into (8), develop the formula $\operatorname{In}(1+\gamma)=\prod_{k=1}^{o o}(-1)^{k+1 \frac{\gamma^{k}}{k}}$ using mathematical formulas [9], $\int \exp (b z) \operatorname{erfc}(a z) d z=\frac{1}{b} \exp (b z) \operatorname{erfc}(a z)-\exp \left(\frac{b^{2}}{4 a^{2}}\right) \operatorname{erf}\left(\frac{b}{2 a}-a z\right)$. In MIMO/FSO, the average capacity of log-normal can be represented by (11),

$$
\begin{aligned}
\left\langle\frac{\bar{C}}{B}\right\rangle= & \frac{\xi^{2} \times e^{b-2 c}}{2 \ln 2 \sqrt{\pi}(c+1)\left(A_{0} X_{l}\right)^{\xi^{2}}} \frac{1}{-0.5 \xi^{2}} \times \sum_{k=1}^{\infty} \frac{(-1)^{k+1}}{k} \times \frac{1}{\xi^{2}+2 k-2}\left(\exp \left(\xi^{2}+2 k-2\right) \operatorname{erfc}\left(\frac{t}{\sqrt{2} \sigma_{I}}\right)-\exp \right. \\
& \left(\frac{1}{2} \sigma_{I}^{2}\left(\xi^{2}+2 k-2\right)^{2} \operatorname{erfc}\left(\frac{\sigma_{I}}{\sqrt{2}}\left(\xi^{2}+2 k-2\right)-\frac{t}{\sqrt{2} \sigma_{I}}\right)\right)
\end{aligned}
$$

where $c=a-\ln \left(\bar{\gamma} A_{0}^{2} X_{1}^{2}\right), t=0.5 \ln \gamma+c$.

Substituting (10) into (8), the average capacity of the MIMO/FSO system for gamma-gamma can be given by (12),

$$
\begin{aligned}
\left\langle\frac{\bar{C}}{B}\right\rangle= & \frac{\xi^{2}(\alpha \beta)^{c+1}}{(c+1)\left(A_{0} X_{l}\right) \Gamma(\alpha) \Gamma(\beta) 2 \ln (2)} \times \\
& \frac{1}{\bar{\gamma}_{m n}} \int_{\Gamma} \ln \left(1+\gamma_{m n}\right) \times G_{1,3}^{3,0}\left[\alpha \beta \frac{(\gamma / \bar{\gamma})^{0.5}}{A_{0} X_{l}} \mid \begin{array}{l}
\xi^{2} \\
\xi^{2}-1, \alpha-1-c, \beta-1-c
\end{array}\right] d \gamma_{m n}
\end{aligned}
$$

Using function Meijer $G, G_{m n}^{p q}[\cdot]$, and use the function expansion $\ln (1+x)=G_{2,2}^{1,2}\left[\left.x\right|_{1,0} ^{1,1}\right]$. The (12) is written as (13).

$$
\begin{aligned}
& \left\langle\frac{\bar{C}}{B}\right\rangle=\frac{\xi^{2}(\alpha \beta)^{c+1}}{(c+1)\left(A_{0} X_{l}\right) \Gamma(\alpha) \Gamma(\beta) 2 \ln (2)} \frac{1}{\bar{\gamma}_{m n}} \times \\
& \times \int_{0}^{\infty} G_{2,2}^{1,2}\left[\left(\gamma_{m n} / \bar{\gamma}_{m n}\right)^{0,5} \mid \begin{array}{l}
1,1 \\
1,0
\end{array}\right] \times G_{1,3}^{3,0}\left[\alpha \beta \frac{\left(\gamma_{m n} / \bar{\gamma}_{m n}\right)^{0,5}}{A_{0} X_{l}} \mid \begin{array}{l}
\xi^{2} \\
\xi^{2}-1, \alpha-1-c, \beta-1-c
\end{array}\right] d \gamma .
\end{aligned}
$$

Performing the multiplication of the two Meijer G functions and applying the integral property. The ACC of AF relay-assisted MIMO/FSO systems with moderate to strong atmospheric turbulence can be given by (14). 


$$
\left\langle\frac{\bar{C}}{B}\right\rangle=\frac{\xi^{2}(\alpha \beta)^{c+1}}{(c+1)\left(A_{0} X_{l}\right) \Gamma(\alpha) \Gamma(\beta) 2 \ln (2)} \frac{1}{\bar{\gamma}_{m n}} \times G_{3,5}^{5,1}\left[\frac{\alpha \beta}{A_{0} X_{l}} \mid \begin{array}{l}
-1, \xi^{2} \\
-1,-1, \xi^{2}-1, \alpha-1-c, \beta-1-c
\end{array}\right]
$$

\section{NUMERICAL RESULTS}

The (11) and (14) can determine the average channel capacity for different atmospheric turbulence and misalignment fading. In (11) is used for log-normal distribution model in case of weak turbulence, while the other is used for gamma-gamma distribution model in the case moderate to strong turbulence. In the results, the value of average channel capacity is evaluated for value of turbulence strength $\left(C_{n}^{2}\right)$, different MIMO configurations, link distance $L(L=4000 \mathrm{~m}$ ), different values of number relay stations $c$ (with $c=0$, $c=1$, and $c=2$ ), and amplification gain $P_{A F}=2 d B$. The constants and parameters are given in Table 1 .

Table 1. System parameters and constants

\begin{tabular}{ccc}
\hline Parameter & Symbol & Value \\
\hline Laser wavelength & $\lambda$ & $1550 \mathrm{~nm}$ \\
Photo detector responsivity & $\Re$ & $1 \mathrm{~A} / \mathrm{W}$ \\
Modulation index & $\kappa$ & 1 \\
Total noise variance & $N_{0}$ & $10^{-7} \mathrm{~A} / \mathrm{Hz}$ \\
In-phase, Quadrature signal amplitudes & $M_{I}, M_{Q}$ & 8,4 \\
The number of relay stations & $c$ & $0,1,2$ \\
Index of refraction structure & $C_{n}^{2}$ & $10^{-15} \mathrm{~m}^{-2 / 3}$ \\
Link distance & $L$ & $4000 \mathrm{~m}$ \\
\hline
\end{tabular}

Figures 2 and 3 illustrate the ASE of average SNR with respect to $\bar{\gamma}$, for three values of the misalignment displacement standard $\sigma_{S}$, with link distances $L=4000 \mathrm{~m}$, for different channel configurations and amplification gain $P_{A F}=2 d B$ in the case moderate to strong, $C_{n}^{2}=3 \times 10^{-14} \mathrm{~m}^{-2 / 3}$. It is observed that the average channel capacity depends on the channel configurations and misalignment displacement standard, especially when increasing channel configuration and high regions of SNR. The ASE under the turbulence conditions is higher than in the cases of moderate and strong turbulence. It has been observed that with an increase in the value of $\mathrm{c}$, (Figure 2, c=10, and Figure 3, c=1) capacity performance of the system deteriorates.

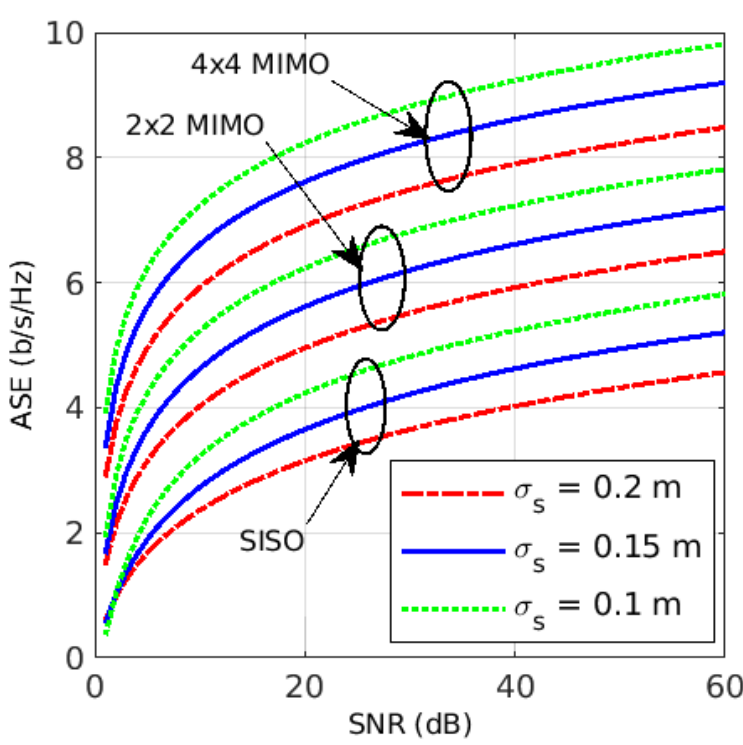

Figure 2. ASE versus average SNR for $8 \times 4$ QAM with different MIMO configurations, SISO, $2 \times 2$ and $4 \times 4$, misalignment displacement standard $\sigma_{s}$ and $\mathrm{c}=0, \mathrm{~L}=4000 \mathrm{~m}$

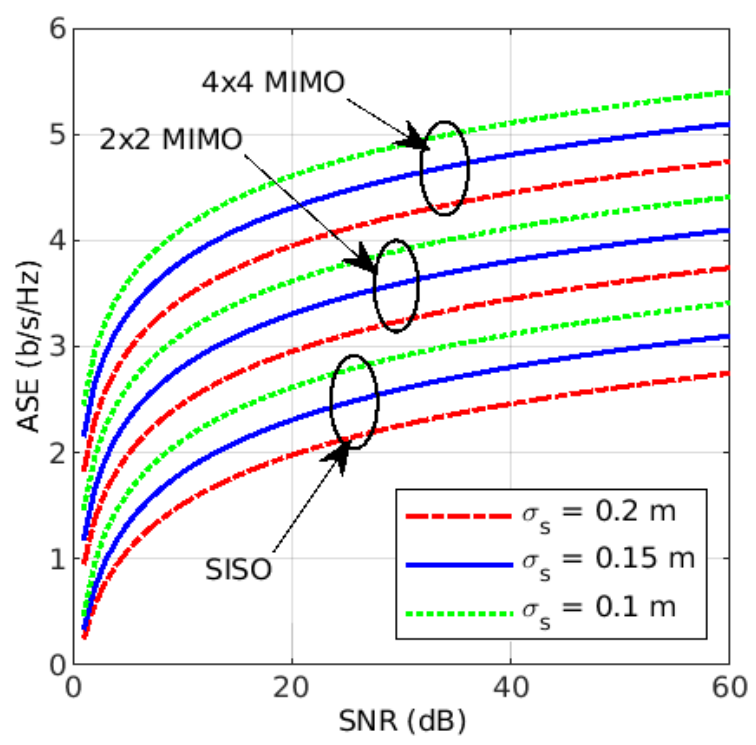

Figure 3. ASE versus average SNR for $8 \times 4$ QAM with different MIMO configurations, SISO, $2 \times 2$ and

$4 \times 4$, misalignment displacement standard $\sigma_{s}$ and $\mathrm{c}=1, \mathrm{~L}=4000 \mathrm{~m}$ 
Figure 4 illustrate the ASE of average SNR with respect to $\bar{\gamma}$, for three values of the misalignment displacement standard $\sigma_{s}$, with link distances $L=4000 \mathrm{~m}$, for different channel configurations, amplification gain $P_{A F}=2 \mathrm{~dB}$, number relay station $\mathrm{c}=2$ for strong atmospheric turbulence, $C_{n}^{2}=3 \times 10^{-14} \mathrm{~m}^{-2 / 3}$. The results in this case change significantly from Figure 4 when the number of relay stations is increased by $c=2$. Specifically, as the value of the relay station increases, the value of the channel capacity decreases, this change is larger for the higher configuration. Figure 5 illustrates the ASE versus the number relay station in the case weak to strong atmospheric turbulence and channel configurations with distance $L=4000 \mathrm{~m}$. The results are in agreement with the conclusions in the figures, it represents the dependence of the channel capacity on the system parameters.

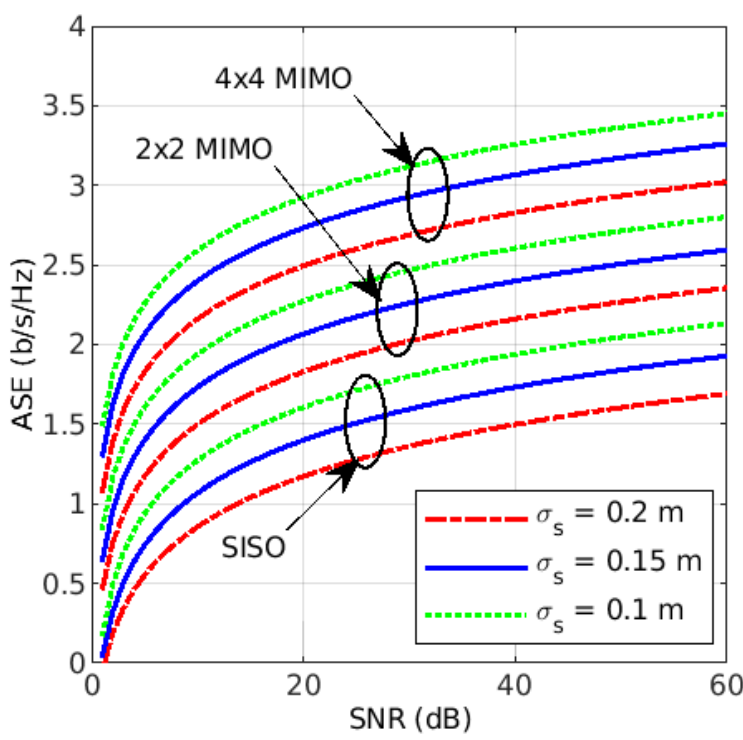

Figure 4. ASE versus average SNR for $8 \times 4$ QAM with different MIMO configurations, SISO, $2 \times 2$ and $4 \times 4$, misalignment displacement standard $\sigma_{s}$ and $\mathrm{c}=2, \mathrm{~L}=4000 \mathrm{~m}$

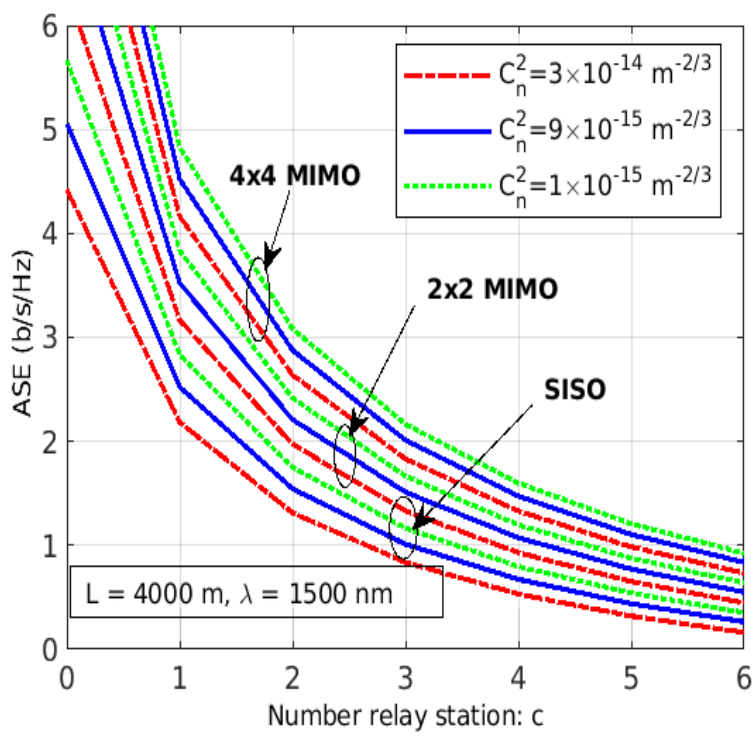

Figure 5. ASE versus the number relay station, cwith different MIMO configurations, SISO, 2x2 and 4x4, link distance, $\mathrm{L}=4000 \mathrm{~m}$, operational wavelength 1500 nmand $8 \times 4$ QAM scheme

\section{CONCLUSION}

This paper has theoretically analyzed misalignment fading effects on the average channel capacity performance of AF relay-assisted MIMO/FSO systems. The gamma-gamma and log-normal distribution models were used to describe the optical propagation fluctuation over atmospheric turbulence channels. The MIMO/FSO model is examined using subcarrier quadrature amplitude modulation and relay stations over atmospheric turbulence channels. The article has built an analytical expression of channel capacity for the cases of log-normal and gamma-gamma for MIMO/FSO system. Based on the theoretical expressions for ASE, the performance of SISO and MIMO systems is strongly affected by the number of AF relay stations, MIMO configurations, and turbulence conditions.

\section{REFERENCES}

[1] K. Majumdar, "Free-space laser communication performance in the atmospheric channel," Journal of Optical and Fiber Communications Reports, vol. 2, pp. 345-396, 2005, doi: 10.1007/s10297-005-0054-0.

[2] S. Arnon, "Optical wireless communications," Encyclopedia of Optical Engineering, pp. 1866-1886, 2003.

[3] D. Kedar and S. Arnon, "Urban optical wireless communication networks: the main challenges and possible solutions," in IEEE Communications Magazine, vol. 42, no. 5, pp. S2-S7, May 2004, doi: 10.1109/MCOM.2004.1299334.

[4] J. Akella, M. Yuksel and S. Kalyanaraman, "Error analysis of multi-hop free-space optical communication," IEEE International Conference on Communications, vol. 3, 2005, pp. 1777-1781, doi: 10.1109/ICC.2005.1494647.

[5] M. Safari and M. Uysal, "Relay-assisted free-space optical communication," in IEEE Transactions on Wireless Communications, vol. 7, no. 12, pp. 5441-5449, Dec. 2008, doi: 10.1109/T-WC.2008.071352.

[6] M. Karimi and M. N. Kenari, "BER analysis of cooperative systems in free-space optical networks," in Journal of Lightwave Technology, vol. 27, no. 24, pp. 5639-5647, Dec. 2009, doi: 10.1109/JLT.2009.2032789.

[7] K. Datsikas, K. P. Peppas, N. C. Sagias and G. S. Tombras, "Serial free-space optical relaying communications over gammagamma atmospheric turbulence channels," in IEEE/OSA Journal of Optical Communications and Networking, vol. 2, no. 8, pp. 576-586, Aug. 2010, doi: 10.1364/JOCN.2.000576. 
[8] D. H. Ai and V. L. Nguyen, "BER analysis of amplify-and-forward relaying FSO systems using APD receiver over strong atmospheric turbulence channels," International Journal of Electrical and Computer Engineering (IJECE), vol. 9, no. 5, pp. 3678-3686, Oct. 2019, doi: 10.11591/ijece.v9i5.pp3678-3686.

[9] M. Safari, M. M. Rad and M. Uysal, "Multi-hop relaying over the atmospheric poisson channel: outage analysis and optimization," IEEE Transactions on Communications, vol. 60, no. 3, pp. 817-829, Mar. 2012, doi: 10.1109/TCOMM.2012.010512.100630.

[10] M. A. Kashani, M. M. Rad, M. Safari and M. Uysal, "All-optical amplify-and-forward relaying system for atmospheric channels," in IEEE Communications Letters, vol. 16, no. 10, pp. 1684-1687, Oct. 2012, doi: 10.1109/LCOMM.2012.082012.121066.

[11] E. Bayaki, D. S. Michalopoulos and R. Schober, "EDFA-based all-optical relaying in free-space optical systems," in IEEE Transactions on Communications, vol. 60, no. 12, pp. 3797-3807, Dec. 2012, doi: 10.1109/TCOMM.2012.090512.110198.

[12] D. H. Ai, "Average channel capacity of amplify-and-forward mimo/fso systems over atmospheric turbulence channels," International Journal of Electrical and Computer Engineering (IJECE), vol. 8, no. 6, pp. 148-153, 2018, doi: 10.11591/ijece.v8i6.pp4334-4342.

[13] M. Aggarwal, P. Garg and P. Puri, "Exact capacity of amplify-and-forward relayed optical wireless communication systems," in IEEE Photonics Technology Letters, vol. 27, no. 8, pp. 903-906, 2015, doi: 10.1109/LPT.2015.2399953.

[14] D. H. Ai, D. T. Quang, N. N. Nam, H. D. Trung, D. T. Tuan and N. X. Dung, "Capacity analysis of amplify-and-forward freespace optical communication systems over atmospheric turbulence channels," 2017 Seventh International Conference on Information Science and Technology (ICIST), 2017, pp. 103-108, doi: 10.1109/ICIST.2017.7926500.

[15] J. Li, J. Q. Liu and D. P. Taylor, "Optical communication using subcarrier PSK intensity modulation through atmospheric turbulence channels," in IEEE Transactions on Communications, vol. 55, no. 8, pp. 1598-1606, Aug. 2007, doi: 10.1109/TCOMM.2007.902592.

[16] D. Kumar, P. K. Singya, and V. Bhatia, "ASER analysis of hybrid receiver based SWIPT two-way relay network," IEEE Transactions on Vehicular Technology, Jul. 2021, doi: 10.1109/TVT.2021.3096833.

[17] W. O. Popoola and Z. Ghassemlooy, "BPSK subcarrier intensity modulated free-space optical communications in atmospheric turbulence," in Journal of Lightwave Technology, vol. 27, no. 8, pp. 967-973, Apr. 2009, doi: 10.1109/JLT.2008.2004950.

[18] T. Pham, T. C. Thang, S. Guo and Z. Cheng, "Performance bounds for Turbo-coded SC-PSK/FSO communications over strong turbulence channels," The 2011 International Conference on Advanced Technologies for Communications (ATC 2011), 2011, pp. 161-164, doi: 10.1109/ATC.2011.6027457.

[19] K. P. Peppas and C. K. Datsikas, "Average symbol error probability of general-order rectangular quadrature amplitude modulation of optical wireless communication systems over atmospheric turbulence channels," in IEEE/OSA Journal of Optical Communications and Networking, vol. 2, no. 2, pp. 102-110, Feb. 2010, doi: 10.1364/JOCN.2.000102.

[20] M. Z. Hassan, X. Song and J. Cheng, "Subcarrier intensity modulated wireless optical communications with rectangular QAM," IEEE/OSA J. of Optical Communications and Networking, vol. 4, no. 6, pp. 522-532, Jun. 2012, doi: 10.1364/JOCN.4.000522.

[21] Bayaki, R. Schober and R. K. Mallik, "Performance analysis of MIMO free-space optical systems in gamma-gamma fading," in IEEE Transactions on Communications, vol. 57, no. 11, pp. 3415-3424, Nov. 2009, doi: 10.1109/TCOMM.2009.11.080168.

[22] P. J. Gripeos, H. E. Nistazakis, E. Roditi, G. D. Roumelas, G. S. Tombras, and C. K. Volos, "On the BER performance of OOK FSO links with receivers' diversity and time jitter over strong turbulence channels," 10th International Conference on Modern Circuits and Systems Technologies (MOCAST), Jul. 2021, doi: 10.1109/MOCAST52088.2021.9493393.

[23] D. H. Ai, D. T. Tuan, and H. D. Trung, "Pointing error effects on performance of amplify-and-forward relaying MIMO/FSO systems using SC-QAM signals over log-normal atmospheric turbulence channels," The 8th Asian Conference on Intelligent Information and Database Systems, 2016, pp. 607-619, vol. 9622, doi: 10.1007/978-3-662-49390-8_59.

[24] A. N. Stassinakis, N. A. Androutsos, S. Sinanovic, M. P. Ninos, and H. E. Nistazakis, "On the block error rate of FSO links with diversity over mixture gamma turbulence channels," Journal of Modern Optics, vol. 68, no. 17, pp. 927-935, 2021, doi: 10.1080/09500340.2021.1961901

[25] A. J. Mahdi, W. J. Mazher, and O. N. Ucan, "Impact of pointing error on SISO/MISO drones swarm-based free space optical system in weak turbulence regime," Indonesian Journal of Electrical Engineering and Computer Science (IJEECS), vol. 23, no. 2, pp. 918-926, 2021, doi: 10.11591/ijeecs.v23.i2.pp918-926.

[26] Kazi Shahiduzzaman, Majumder F. Haider, and B. K. Karmaker, "Terrestrial free space optical communications in Bangladesh: transmission channel characterization," International Journal of Electrical and Computer Engineering (IJECE), vol. 9, no. 4, pp. 3130- 3138, 2019, doi: 10.11591/ijece.v9i4.pp3130-3138.

[27] D. H. Ai, H. D. Trung, and D. T. Tuan, "On the ASER performance of amplify-and-forward relaying MIMO/FSO systems using SC-QAM signals over log-normal and gamma-gamma atmospheric turbulence channels and pointing error impairments," Journal of Information and Telecommunication, vol. 4, no.3, pp 1-5, Mar. 2020, doi: 10.1080/24751839.2020.1732734.

\section{BIOGRAPHIES OF AUTHORS}

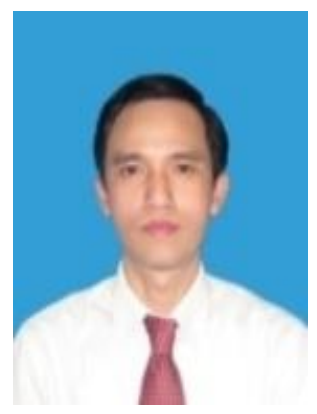

Huu Ai Duong (iD) SC $\mathrm{P}$ received BS degree in Radio and Telecommunications from Hue University of Sciences, Vietnam, in 2003, and M.E degree of Electronic Engineering from Danang University of Technology, Vietnam, in 2011, and $\mathrm{PhD}$ of Electronic and Telecommunications in Hanoi University of Technology, Vietnam, in 2018. Currently, he is a lecturer at The University of Danang, Vietnam-Korea University of Information and Communication Technology, Danang, Vietnam. His research interests include optical wireless communications, optical and quantum electronics, 5G wireless communications and broadband networks and IoT. He can be contacted at email: dhai@vku.udn.vn. 


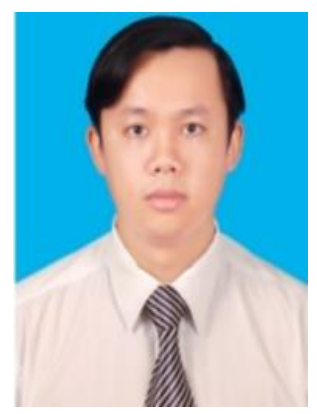

Van Loi Nguyen (D) IS SC P he received his Master of Engineering in Computer Science from the University of Danang, Vietnam in 2010, a Ph.D. degree from Soongsil University in 2017. Currently, he is a lecturer at The University of Danang, Vietnam-Korea University of Information and Communication Technology, Danang, Vietnam. His research interests include multimedia, information retrieval, artificial intelligence, database, and IoT. He can be contacted at email: nvloi@vku.udn.vn.

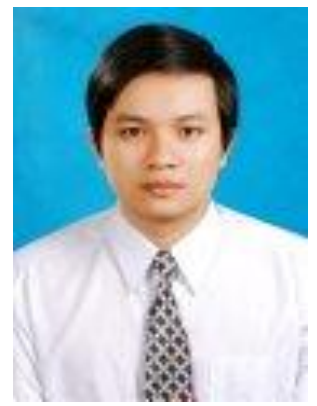

Khanh Ty Luong (iD 8 SC P he received his Master of Engineering in Computer Science from the University of Danang, Vietnam in 2012, and Ph.D. student of Computer Science in Hanoi University of Technology. Currently, he is a lecturer at The University of Danang, Vietnam-Korea University of Information and Communication Technology, Danang, Vietnam. His research interests include database, artificial intelligence, IoT, and optical wireless communications. He can be contacted at email: lkty@vku.udn.vn. 